Mazumdar, S. and Chen, Q. 2008. "Influence of cabin conditions on placement and response of contaminant detection sensors in a commercial aircraft," Journal of Environmental

Monitoring, 10, 71-81.

\title{
Influence of cabin conditions on placement and response of contaminant detection sensors in a commercial aircraft
}

\author{
Sagnik Mazumdar \\ Qingyan Chen, Ph.D. \\ Air Transportation Center of Excellence for Airliner Cabin Environment Research (ACER) \\ School of Mechanical Engineering, Purdue University, West Lafayette, IN 47907-2088
}

Potential causalities due to airborne disease transmission and risk of chem-bio terrorism in commercial airliner cabins can be reduced by fast responses. Fast responses are only possible by using sensors at appropriate locations in the cabins. Cost, size and weight factors restrict the number of sensors that could be installed inside a cabin. Since release locations and seating patterns of passengers can impact airborne contaminant transports, this study first addressed this impact by using a validated Computational Fluid Dynamics (CFD) program in a four-row mockup of twin-aisle airliner cabin. It was observed that occupancy patterns and release locations have little influence on longitudinal contaminant transports though localized variations of contaminant concentrations may exist. The results show that response time of the sensors is considerably reduced with the increase in number of sensors. If only a single sensor is available across a cabin cross-section then it should be placed at the middle of the ceiling. A cabin model of a fully occupied twin-aisle airliner with 210 seats was also build to study the diverse contaminant distribution trends along cabin length. The results reveal that seating arrangements can make cross sectional airflow pattern considerably asymmetrical. Similar airflow patterns make the longitudinal contaminant transport in the business and economy classes alike. The presence of galleys greatly affected the longitudinal transport of contaminants in a particular cabin section. The effects due to galleys were less significant if a multipoint sampling system was used. The multipoint sampling system can also reduce the number of sensors required in a cabin.

\section{INTRODUCTION}

Nearly two billion people travel on commercial airliners each year ${ }^{1}$. The increasing mobility of people has also augmented the potential risk of airborne disease transmission. In March 15, 2003 Air China Flight 112 from Hong Kong to Beijing five people died from SARS after most likely contracting the disease from an infected passenger on the same flight $^{2,3}$. Hence with growing mobility the chances for disease to be transmitted between passengers during the flights have become an important public health issue ${ }^{4}$. Heightened fears of chemical and biological attacks by terrorists have made matters worse. Based on the analysis on Air China passengers the mean incubation period of SARS was found to be 4 days. The incubation periods of some biological agents like Cholera can be as low as 4 hours and can spread rapidly with high lethality without treatment ${ }^{5}$ and hence can create a major pandemic. Moreover some chemical agents can kill passengers immediately.

Sagnik Mazumdar is a Ph.D. candidate, Qingyan (Yan) Chen is a professor in the School of Mechanical Engineering, Purdue University, West Lafayette, IN. 
After the sarin attack in the Tokyo subway in 1995, U.S. Department of Energy Program for Response Options and Technology Enhancements for Chemical/Biological Terrorism in Subways ${ }^{6}$ aimed at developing and applying technologies to save lives in case of a chemical or biological release. Their simulated results show that with rapid response systems the number of fatalities can be reduced from 27,376 to 1135 people in case of an anthrax release and from 4185 to 372 people in case of sarin release ${ }^{7}$. Hence the time it takes to implement system-wide response is critical to saving lives. An effective warning and response system to handle such attacks must incorporate two major components. First, a component to rapidly detect a chemical or biological release and secondly, an effective response plan. The second component can only be effective if the first component works. Sensors, artificial intelligent systems and video technologies can help to rapidly identify and confirm a release. Artificial intelligent systems and video technologies can only help if the chemical or biological release is fast-acting and cause distinctive behavioral changes among people. But this may not be always feasible as is evident from the Air China flight incident where the first onset of symptoms was after two days and there were no recognized exposures to patients with SARS before or after the flight ${ }^{2}$. Hence the universal approach of dealing with chemical/biological releases would be placement of sensors at appropriate locations in the cabin. Thus this study focuses on the issue of effective placement and response of sensors to detect such releases within aircraft cabins.

An obvious solution is to place sensors at the exhaust air from different cabin zones. The current mixing air distribution system in aircraft cabins aids the dilution of airborne biological and chemical contaminants in case of a release ${ }^{8}$. An extremely sensitive sensor would be required in order to address the dilution effect along with high air exchange rates of aircraft cabins. Although the air exchange rate is high in a cabin, the contaminant transport from a source to the exhaust may take a long time. The response time can be long. Moreover, the measured information though useful might not effectively predict the location of the release which is important for an efficient response plan ${ }^{9}$. Thus the sensors need to be placed inside aircraft cabins for fast detection and effective use of its responses. Fast detection is only possible by placing sensors at appropriate locations ${ }^{10}$ inside the cabin. Since sensors systems are often heavy, expensive and bulky, they cannot be deployed in large quantities. Hence the number of sensors installed should be limited.

Zhang et al. ${ }^{11}$ studied optimal placement of contaminant detection sensors for a fully occupied nine-row, twin aisle economy class airliner cabin. But recent experiments in a room suggest that distribution of airborne contaminants can vary significantly for different thermal conditions $^{12}$. Thermal conditions can vary due to different occupancy distributions and passenger capacities inside the cabin. Moreover, the study by Zhai et al. ${ }^{10}$ concluded that contaminant source location is also an important factor for optimal sensor placement for detecting chemical/biological releases. Hence the effect of different source locations needs to be verified, especially along the length of the cabin as diverse flow conditions are expected. This is due to different seating arrangements in different sections of the cabin and also due to the presence of galleys in between sections. This study addresses all the above concerns. 


\section{RESEARCH APPROACH}

Studies towards sensor placements in aircraft cabins can either be done by conducting experimental measurements or using computer simulations. The most realistic information about airflow and contaminant transport can be obtained by on-site measurements. Since measurements have to be made at many locations and the thermo-fluid boundary conditions have to be properly controlled, they are time consuming and expensive. Laboratory experiment seems more affordable and thermo-fluid boundary conditions are easier to control with state-of-the-art experimental facilities. A lot of laboratory measurements of airflow and/or contaminant transport were performed on empty cabin mockups without considering the effects of occupancy ${ }^{13-15}$. Singh et al. ${ }^{16}$ used heated cylinders to approximate the effects of passengers and studied the airflow pattern inside an aircraft cabin. The airflow pattern was obtained using smoke visualization that may not be sufficiently accurate. Mo et al. ${ }^{17}$ measured airflow by using a Particle Image Velocimetry (PIV) system by lowering all the seat backs to facilitate the penetration of the laser beam. This made the cabin conditions very different from the in-flight situation. Recently a non-intrusive VPSV (Volumetric Particle Streak Velocimetry) technique was successfully used by Sun et al. ${ }^{18-19}$ to measure airflow in a five-row mockup cabin simulating in-flight conditions. But the large volume of airspace and obstructions of mannequins prevented them from acquiring detailed airflow data. The thermal buoyancy effect of passengers could not be demonstrated as well. Moreover, threedimensional velocity measurements could not be performed due to the limited capabilities of the sequential image processing technique. It is evident that even laboratory measurements with good spatial and temporal resolutions to study the effects of varying parameters like thermal loads, contaminant source locations etc. are difficult. Moreover, it may not be realistic to have a mockup of a large aircraft to study the effect of source location along cabin length and conduct a large number of measurements to test the repeatability of the results. Thus an experimental study would be time consuming, expensive and difficult.

As compared to experimental investigations, computer simulations seem a cheaper and more efficient alternative. Multizone network models and Computational Fluid Dynamics (CFD) simulation models have both been used extensively to predict airflows and contaminant transport in enclosed spaces. Though multizone models are fast and have been effectively used to optimize chemical/biological sensor placements ${ }^{20}$ with due modifications, yet the models assume fast mixing in each zone that can lead to inaccurate results. For non-uniform contaminant distributions the results of a multizone model has been found to be questionable ${ }^{21}$. Moreover, the air circulation patterns in most commercial aircraft have little airflow in longitudinal direction ${ }^{22}$ hence the risk of infectious disease transmission from a contagious passenger to fellow passengers is limited to one or two rows ${ }^{2,23}$. Hence the effect of contaminant released in particular zone of a cabin is expected to remain localized and confined within that zone thus making multizone models inappropriate for such a study. CFD simulations seem to be the only viable alternative.

CFD techniques have provided encouraging results for diverse indoor environmental studies ${ }^{24}$. The techniques have been used effectively to obtain flow fields and contaminant transmission in commercial aircraft cabins ${ }^{13,16,25,26}$. Zhang et al. ${ }^{11}$ successfully used the CFD program FLUENT to study optimal sensor placement in aircraft cabins. Since most CFD models use approximations, they validated the CFD program with the measured air velocity, 
air temperature, and gaseous contaminant distributions in a four-row mockup of a twin-aisle aircraft cabin ${ }^{27}$. Their study used Re-Normalization Group (RNG) $k-\varepsilon$ model to simulate turbulent flow as suggested by Chen to model indoor airflows ${ }^{28}$. Figure 1 shows the schematic of the cabin configuration. The mockup had 28 seats in four rows. Only 50\% of the seats were occupied by heated manikins. Our validation used the same cabin mockup and turbulence model with similar thermo-fluid settings as shown in Table 1. The CFD modeling used the second-order upwind scheme and SIMPLE algorithm with a segregated steady state solver. The steady state segregated solver was also used to compute the contaminant concentration distribution with fixed airflow pattern. A continuous $\mathrm{SF}_{6}$ source was introduced at the head level of the middle passenger seated in the third row to simulate an airborne contaminant source, such as infectious disease viruses or chemical/biological agents. The steady state $\mathrm{SF}_{6}$ concentrations at different heights were measured using sampling tubes mounted on poles which extracted cabin air to a photo acoustic multi-gas monitor. The accuracy of the measurements was $0.005 \mathrm{~m} / \mathrm{s}$ for velocity and $0.025^{\circ} \mathrm{C}$ for air temperature with $1 \%$ error. The measurement accuracy of $\mathrm{SF}_{6}$ concentration was $0.01 \mathrm{ppm}$ and the repeatability was $1 \%$ of the measured values.

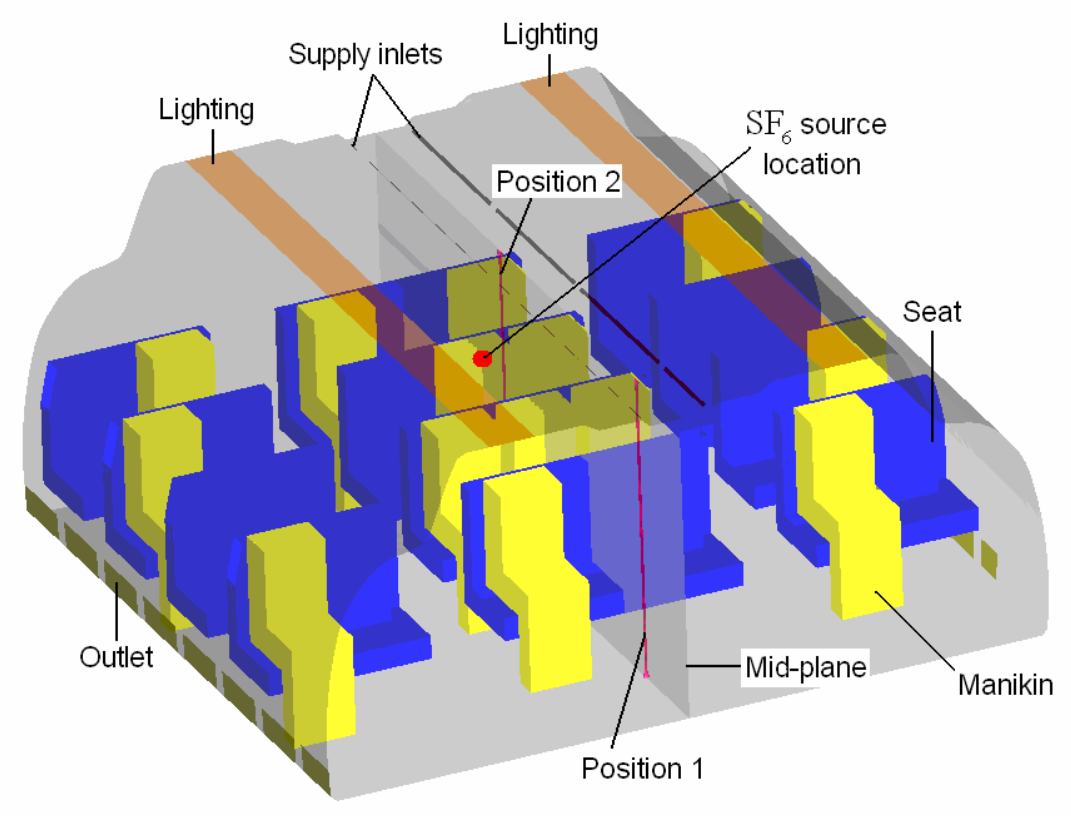

Fig. 1. Schematic of the mockup two-aisle aircraft cabin used for validation 
Table 1. Boundary conditions for the cabin mockup

\begin{tabular}{|c|c|c|c|}
\hline Supply airflow rate & $0.23 \mathrm{~m}^{3} / \mathrm{s}$ & $\begin{array}{c}\text { Floor temperature under } \\
\text { side seats }\end{array}$ & $24.4^{\circ} \mathrm{C}$ \\
\hline Supply air temperature & $19.3^{\circ} \mathrm{C}$ & Aisle temperature & $24.8^{\circ} \mathrm{C}$ \\
\hline $\begin{array}{c}\text { Ceiling temperature } \\
\text { between inlets }\end{array}$ & $23.8^{\circ} \mathrm{C}$ & $\begin{array}{c}\text { Floor temperature under } \\
\text { central seats }\end{array}$ & $25.1^{\circ} \mathrm{C}$ \\
\hline $\begin{array}{c}\text { Temperature of the } \\
\text { ceiling between inlets } \\
\text { and lighting }\end{array}$ & $26.4^{\circ} \mathrm{C}$ & $\begin{array}{c}\text { Front/Back wall } \\
\text { temperatures }\end{array}$ & $24.7^{\circ} \mathrm{C}$ \\
\hline $\begin{array}{c}\text { Temperature of the } \\
\text { sidewalls }\end{array}$ & $24.5^{\circ} \mathrm{C}$ & $\begin{array}{c}\text { Temperature of the } \\
\text { manikins }\end{array}$ & $31{ }^{\circ} \mathrm{C}$ \\
\hline $\begin{array}{c}\text { Supply air SF } \\
\text { concentration }\end{array}$ & $0.10 \mathrm{ppm}$ & $\begin{array}{c}\text { Exhaust air SF } \\
\text { concentration }\end{array}$ & $0.32 \mathrm{ppm}$ \\
\hline
\end{tabular}

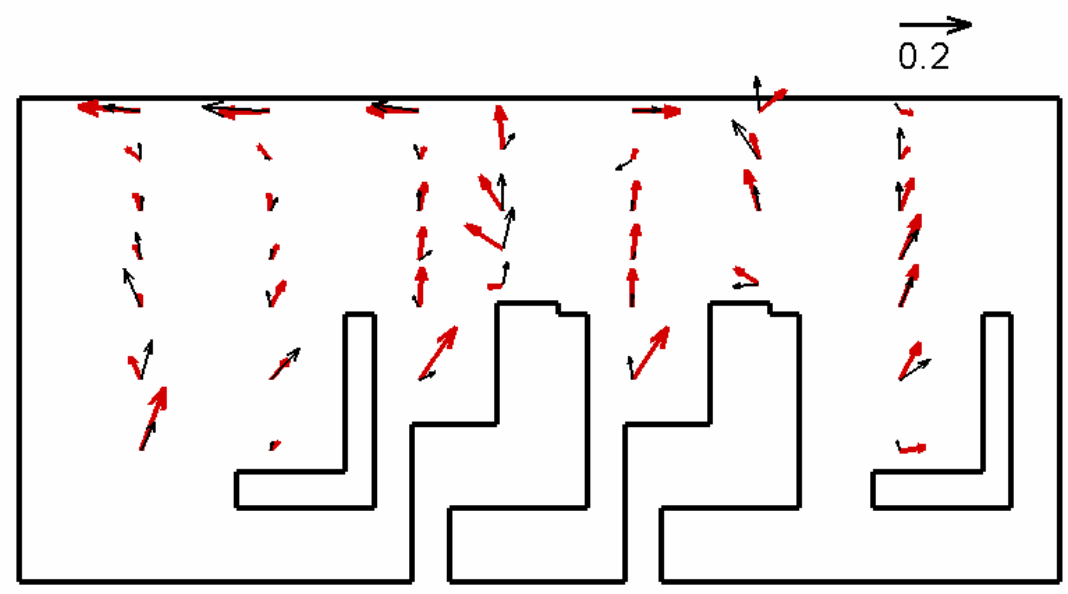

(a)

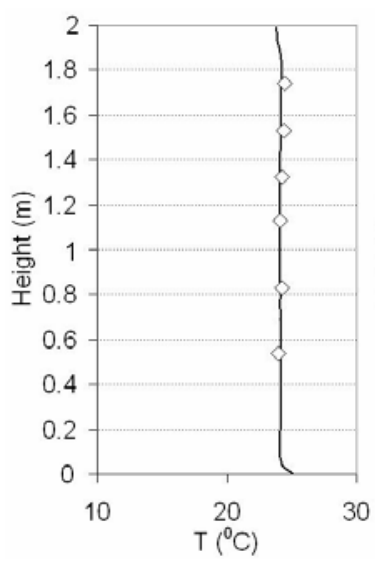

Position 1

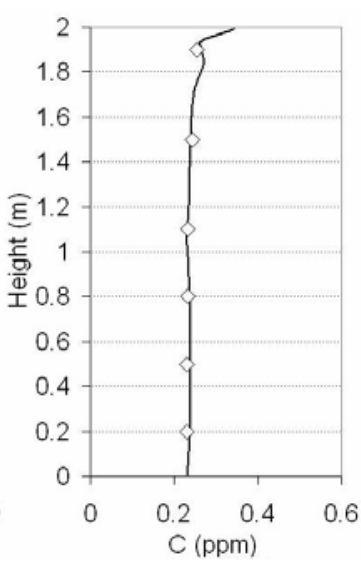

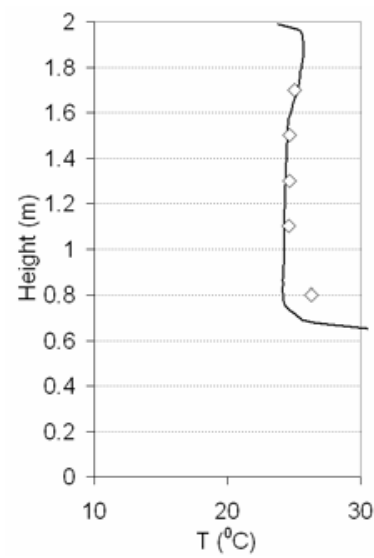

Position 2

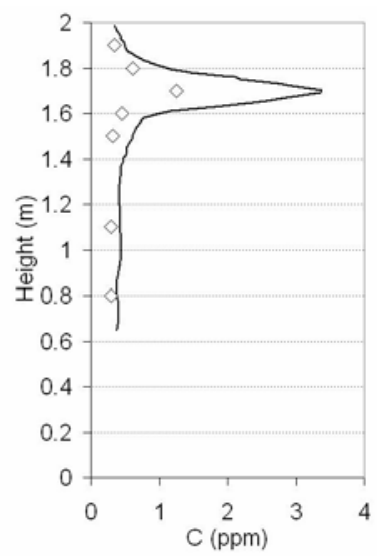

(b)

Fig. 2. A comparison between (a) the CFD (black arrows) and measured (red arrows) velocity profiles at mid-plane; (b) the CFD results (lines) and experimental data $(\diamond)$ for air temperature (T) and $\mathrm{SF}_{6}$ concentration $(\mathrm{C})$ at positions 1 and 2 
Figure 2(a) shows the airflow pattern in the longitudinal direction along the mid-plane of the cabin. The CFD model could capture the global airflow trends like the division of two streams above the second-row seat. But the calculated thermal plume from the passengers was not as strong as the measured one probably due to the use of uniform manikin surface temperature in the CFD simulation. It was difficult to obtain uniform surface temperature during the experiment. Figure 2(b) further compares the experimental and computed profiles of air temperature and $\mathrm{SF}_{6}$ concentration at two different pole positions indicated in Figure 1. In general, the CFD predictions match well with the experimental data except the $\mathrm{SF}_{6}$ concentrations close to the $\mathrm{SF}_{6}$ source (Position 2). The airflow near the source location was not steady which caused difficulties in both the measurements and simulations. It is difficult to ascertain whether the measured value is more accurate. The $\mathrm{SF}_{6}$ concentrations could only be measured every $30 \mathrm{~s}$ and hence can result in significant errors if the flow during this period was not steady. Similar problems of unstable and locally complicated flows were observed by Yuan et al..$^{29}$ and $\mathrm{He}$ et al. ${ }^{30}$ in rooms with displacement ventilation. As measurement devices with better time resolutions become available, exact comparisons of concentrations close to the contaminant source would then be feasible.

Since this study obtained the same accuracy in predicting airflow, air temperature and gaseous contaminant distributions as those reported by Zhang et al. ${ }^{11}$, hence the CFD program FLUENT with RNG $k-\varepsilon$ model is used for this study. Moreover, though the validation is done for a steady-state case, we presume that transient contaminant simulations performed later in the study is reliable. Due to transient nature of contaminant dispersion and low resolution in the experiment, it is difficult to compare CFD predictions with experimental measurements. Only recently there have been studies for isothermal flow conditions where small scale experimental models with high spatial and temporal resolution concentration maps have been validated with CFD predictions ${ }^{31}$. Initial studies demonstrate that Reynolds Averaged Navier-Stokes (RANS) turbulence model provides good predictions for both transient and steady state pollutant concentrations for isothermal flows. The approaches adopted in these studies were similar to that used in our investigation, i.e. solving the concentration distributions with a fixed airflow pattern. In addition, the aircraft cabin geometry is far more complicated than rooms. Hence obtaining experimental data with very good temporal resolution for CFD validation in a full scale aircraft cabin is difficult at this stage. Nevertheless, the CFD solutions should be trustable if the agreement under steady state is good, because a transient state is a path to the steady state ${ }^{32}$. Hence the CFD program FLUENT with RNG $k-\varepsilon$ model is used to further study the effect of different cabin conditions on steady and transient contaminant transports in aircraft cabins. 


\section{CASE SETUP}

The study used two different cabin geometries to analyze the effect of diverse cabin conditions on contaminant transport. Since the risk of infectious disease transmission is limited to one or two rows from a contagious passenger ${ }^{2,23}$, the effects of passenger capacity and contaminant source locations is studied using a four-row, twin-aisle aircraft cabin section. A full-length cabin model was then used to examine diverse contaminant distribution patterns along the cabin length. The use of two different cabins reduced computational efforts without losing information.

The four-row cabin model used the same cross-sectional geometry and human models as those used by Lin et al. ${ }^{25,26}$. Each row had seven seats numbered A-L as shown in Figure 3. The human model had a head, torso, thigh, legs and feet. There were two linear inlets at the ceiling of the cabin which supplies conditioned air to both the sides of the cabin. The air was extracted from the outlets located at floor level near the side walls. The temperature boundary conditions for the walls in both geometries were obtained from on-site measurements ${ }^{8}$ and are shown in Table 2. The effect of different cabin conditions on contaminant transport was analyzed based on the response of contaminant detection sensors. Sensor response can get affected due to anomaly in passenger behavior if the sensor is placed in the zone of occupancy. Hence overhead locations and outlets are the best possible place to place the sensors. Figure 3 shows the sensor locations analyzed in this study.
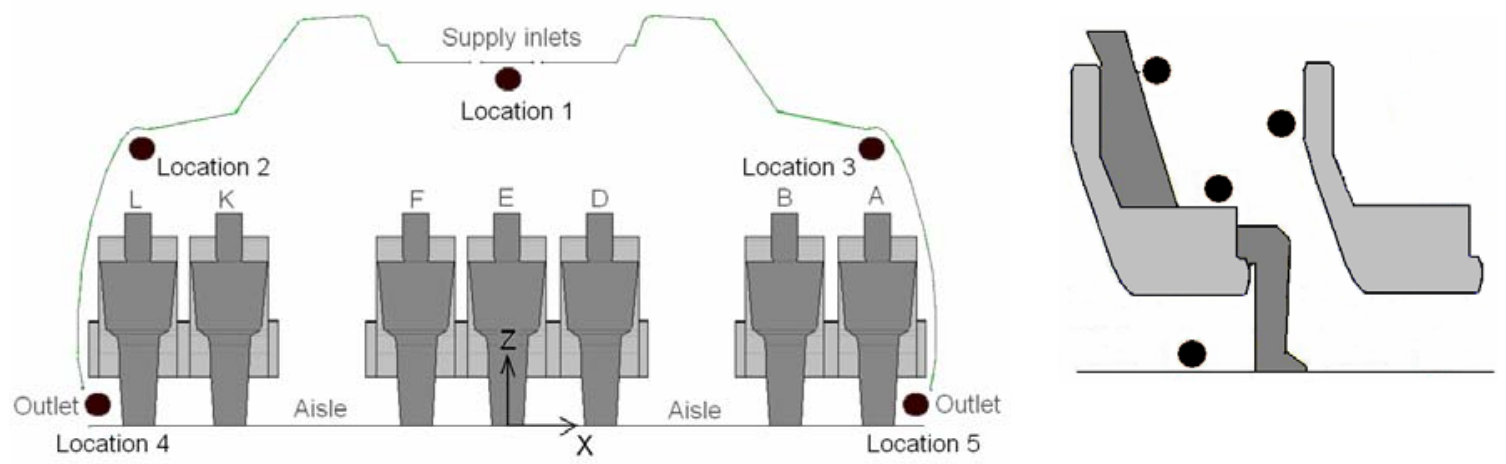

Fig. 3. A section of the twin-aisle cabin with sensor (left) and contaminant source locations (right)

Table 2. Thermal boundary conditions used for the cabin geometries

\begin{tabular}{|c|c|c|c|}
\hline Supply air & $19.5^{\circ} \mathrm{C}$ & Floor under side seats & $23{ }^{\circ} \mathrm{C}$ \\
\hline Ceiling within inlets & $25^{\circ} \mathrm{C}$ & Windows & $13{ }^{\circ} \mathrm{C}$ \\
\hline $\begin{array}{c}\text { Ceiling } \\
\text { (from inlets to lights) }\end{array}$ & $23{ }^{\circ} \mathrm{C}$ & Passengers & $30.3{ }^{\circ} \mathrm{C}$ \\
\hline Side walls & $18^{\circ} \mathrm{C}$ & Lighting & 12.5 W/row \\
\hline Floor under center seats & $24{ }^{\circ} \mathrm{C}$ &
\end{tabular}


The effect of different occupancy distributions and passenger capacities on the responses of the contaminant detecting sensors was studied for four different occupancy patterns, as shown in Figure 4. Pattern 1 denotes a seating pattern with occupancy more in front of the cabin while the reverse is true for Pattern 3. Pattern 4 denotes a case where the occupancy is skewed towards one side while Pattern 2 denotes a fully occupied cabin. The trends obtained using these four patterns would hold true for other passenger distributions as well which would become evident from the results presented later in this paper. The study also addresses the impact of different contaminant source locations. Four different contaminant source locations studied were from the mouth, near the hand, near the leg, and near the seat back in front of the passenger (refer to Fig. 3). This study assumed that contaminants were released at the four locations from passengers $\mathrm{A}, \mathrm{E}$ and $\mathrm{K}$ in the third row who are seated next to the window, in the middle, and next to the aisle, respectively. This leads to a total of 4 source locations $\mathrm{x} 3$ passengers $\mathrm{x} 4$ seating patterns $=48$ scenarios. Steady-state contaminant transport was studied for these 48 scenarios. Since sensor response time is also a crucial factor in placing of the sensors, unsteady contaminant transport was obtained for sources from the mouth and leg only, i.e. a total of 24 scenarios. The infectious disease viruses or chemical/biological agent was simulated as a gaseous contaminant in the present study. This approach is supported by the findings of Memarzadeh and Jiang ${ }^{33}$ and Seymour $^{34}$. The results obtained were for a moderate continuous contaminant release rate of $1.0 \times 10^{-6} \mathrm{~m}^{3} / \mathrm{s}$ as proposed by Zhang et al. ${ }^{11}$. The results can be easily scaled up or down to address other release rates. The contaminant concentration from the supply air was assumed to be zero. Periodic boundary conditions were used at the end faces to simulate flow conditions similar to an infinitely long air cabin.
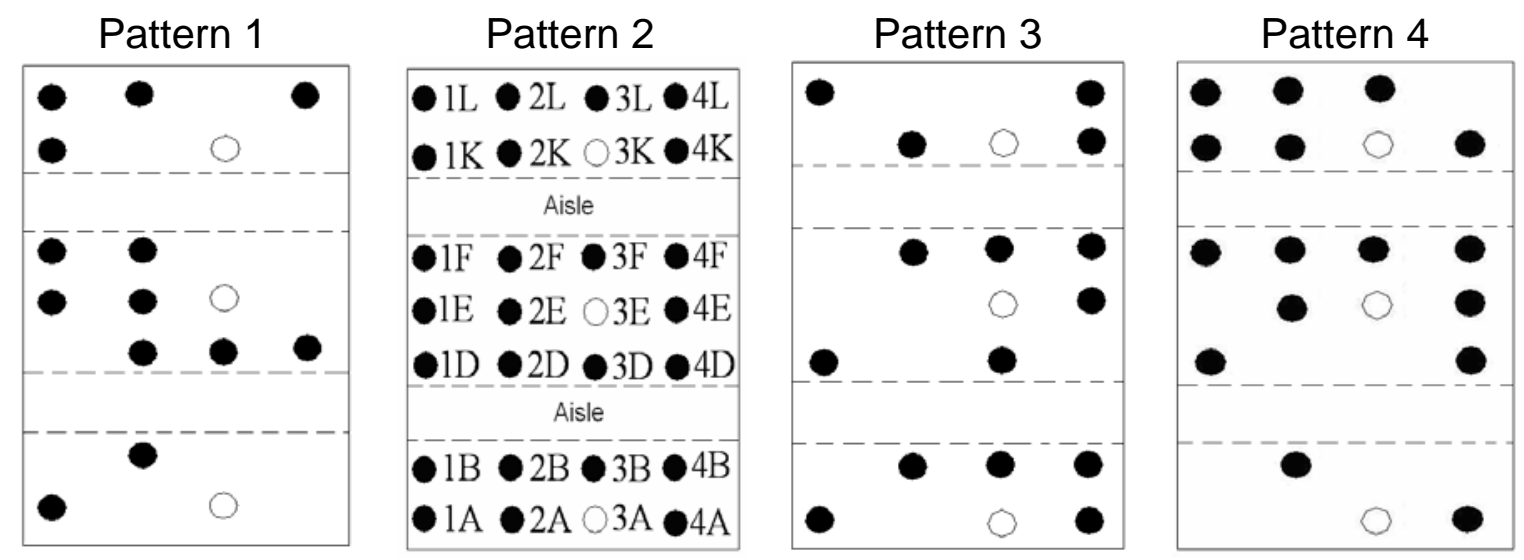

Fig. 4. Schematic of the occupancy patterns in the plane view $(0=$ passengers with contaminant source, $\bullet=$ passengers without contaminant source, 1-4 $=$ row number, A$\mathbf{L}=$ seat number)

The full length cabin model shown in Fig. 5 was used to study the contaminant distribution patterns at different source locations along the longitudinal direction. It had 18 seats in the first class, 42 in business class, and 150 in economy class. The seat pitches were $1.52 \mathrm{~m}, 0.97$ $\mathrm{m}$, and $0.86 \mathrm{~m}$ for the first, business, and economy class, respectively. The model considered the cabin to be fully occupied. This study used eight contaminant sources from the window 
passengers for reasons highlighted later in the study: two from the first class (F1, F2), three from the business class (B1-B3), and three from the economy class (E1-E3). The airflow rate in the economy class was $10 \mathrm{~L} / \mathrm{s}$ per passenger ${ }^{8}$. The geometry of the human manikins was also simplified compared to the four-row cabin so that courser computational meshes could be used near the manikins. Box-shaped manikins were used to represent the passengers since Topp et $a l .{ }^{35}$ found that they were sufficient for the study of global airflow in a space. The total surface area of a manikin was about $1.8 \mathrm{~m}^{2}$. Moreover, the simulations did not consider the effects of heat sources and sinks from electronic devices, drinks and meals.

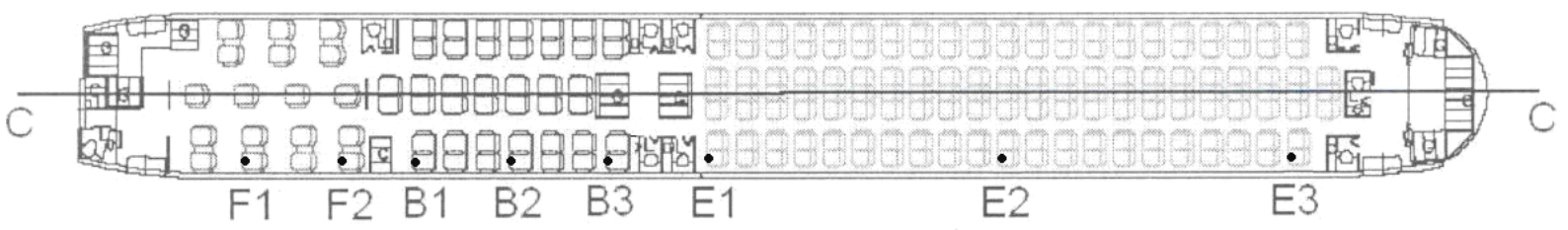

Fig. 5. Layout of a whole twin-aisle cabin used and the contaminant source locations

In addition to the above thermo-fluid boundary conditions, the CFD modeling used the second-order upwind scheme and SIMPLE algorithm with a segregated steady-state solver. However both the steady and unsteady state segregated solvers were used to compute the contaminant concentration distribution with fixed airflow pattern. Since the four-row cabin geometry used a fairly detailed human model and inlet boundary conditions as used by Lin et $a .^{25,26}$, very fine mesh distributions had to be used. This resulted in a total of 2.4 million tetrahedral cells for the four-row cabin. The full length cabin used box shaped manikins and a mean supply air velocity to reduce computational mesh requirements. Grid independence study performed by $\mathrm{Chen}^{36}$ tested three different mesh sizes of $4 \mathrm{~cm}, 6 \mathrm{~cm}$ and $8 \mathrm{~cm}$ respectively for a four row economy class cabin section. The values of contaminant concentrations were compared at nine different pole positions. No considerable variation in contaminant concentrations were observed below the grid size of $6 \mathrm{~cm}$. The $6 \mathrm{~cm}$ grid resulted in a total of 10.2 million tetrahedral cells for the full-length cabin.

A Linux computer cluster was used to compute the cases. Each node of the cluster had two processors (1.8 GHz AMD 64) and 4GB of memory. The CFD computations were terminated when the residual for mass (sum of the absolute residuals in each cell/the total mass inflow) and the residual for energy (sum of the absolute residuals in each cell/the total heat gains) was less than $0.1 \%$ and $1 \%$ respectively. The contaminant concentration calculation was stopped when the cumulative normalized residual on the transport equation dropped below $1.0 \times 10^{-5}$. Though a lot of contaminant release scenarios were studied, the results presented are for a few specific cases only to maintain brevity of the paper. The conclusions drawn are from all the cases studied. 


\section{RESULTS AND DISCUSSION}

\section{Impact of source locations and occupancy patterns}

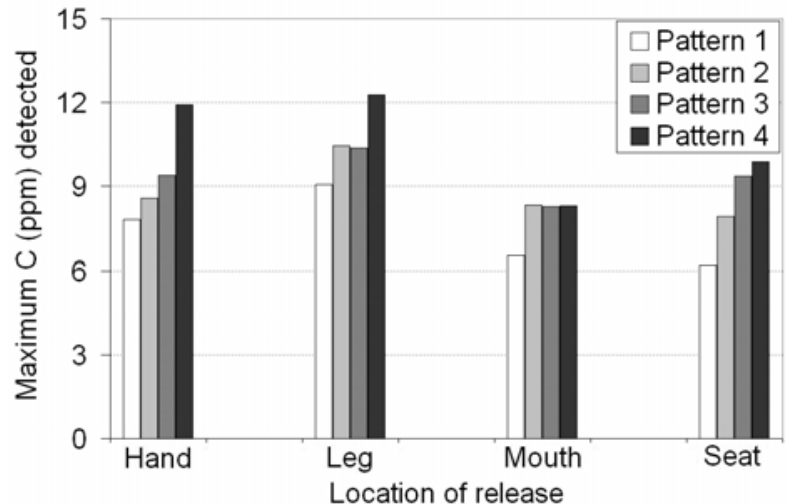

(a)

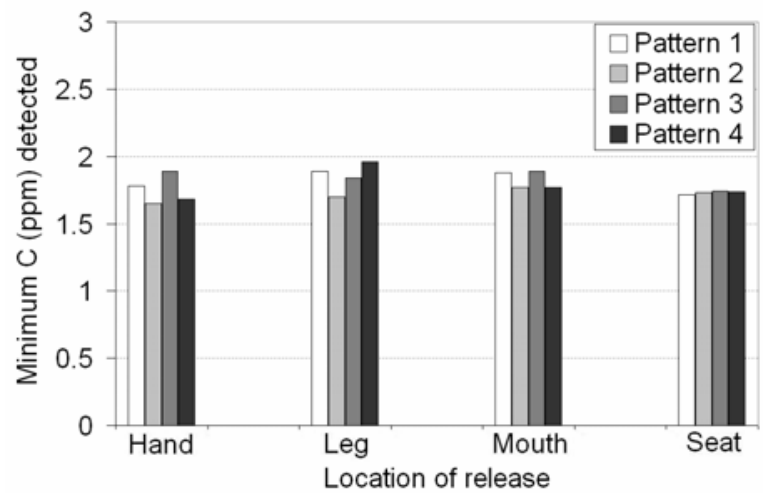

(b)

Fig. 6. Maximum and minimum steady state contaminant concentrations detected at the location 1 for different sources near passenger $3 \mathrm{~K}$

The seating patterns of passengers may have an impact on contaminant transport. The variation in contaminant transport for different occupancy patterns and source locations is shown in Fig. 6. The figure shows the maximum and minimum steady-state contaminant concentrations detected at the ceiling center location 1 . The results are presented for different contaminant sources near passenger $3 \mathrm{~K}$. The maximum concentration detected at location 1 varied considerably since the localized airflow can vary significantly for different seating patterns. The effect of seating patterns on local airflows is shown in Fig. 7. The thermal plume from the middle passenger in the third row shifted towards the empty seats at its sides thus affecting the structure of the two major local flow circulations observed at the cabin cross-section. This restructuring of the flow circulations caused better localized transfer of contaminants released near passenger $3 \mathrm{~K}$ to location 1 for occupancy pattern 4 compared to the other patterns. Moreover the maximum concentrations detected for contaminant released near the hand and leg of passenger $3 \mathrm{~K}$ was higher. This happened because contaminants released from the mouth and seat back of passenger $3 \mathrm{~K}$ was carried towards the side wall and outlet due to the effect of the incoming jet of air before it merged with the flow stream coming towards location 1 . Thus contaminants released from the leg and hand of passenger $3 \mathrm{~K}$ had to travel a lesser convective path to reach location 1 than released from the mouth and seat back. Hence local airflows can have significant variations in local contaminant transport. Fig. 6(b) also shows that less variation was observed in the minimum concentration detected at location 1 . The minimum concentration detected was the measure of variation in longitudinal contaminant transport for different cases. The difference in longitudinal contaminant transport between the cases was not much as the global longitudinal airflow patterns remain similar. 


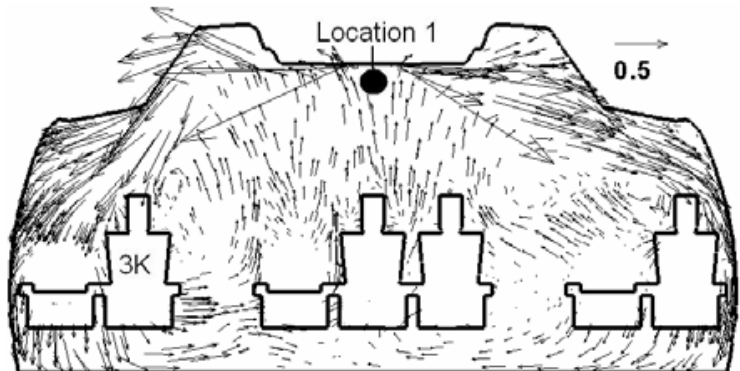

(a)

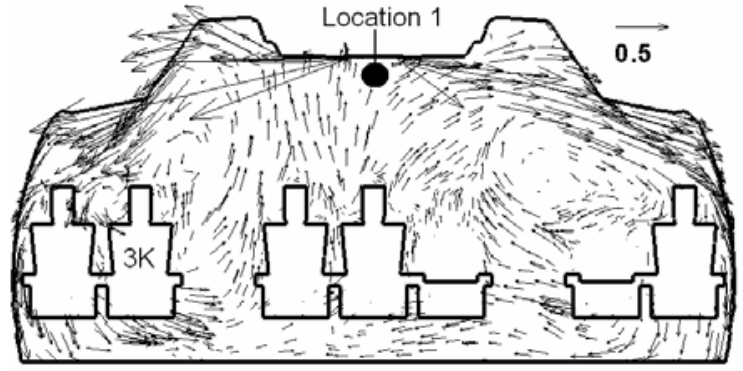

(b)

Fig. 7. Representative airflow patterns along the cross sectional direction for (a) Pattern 1 and (b) Pattern 4.

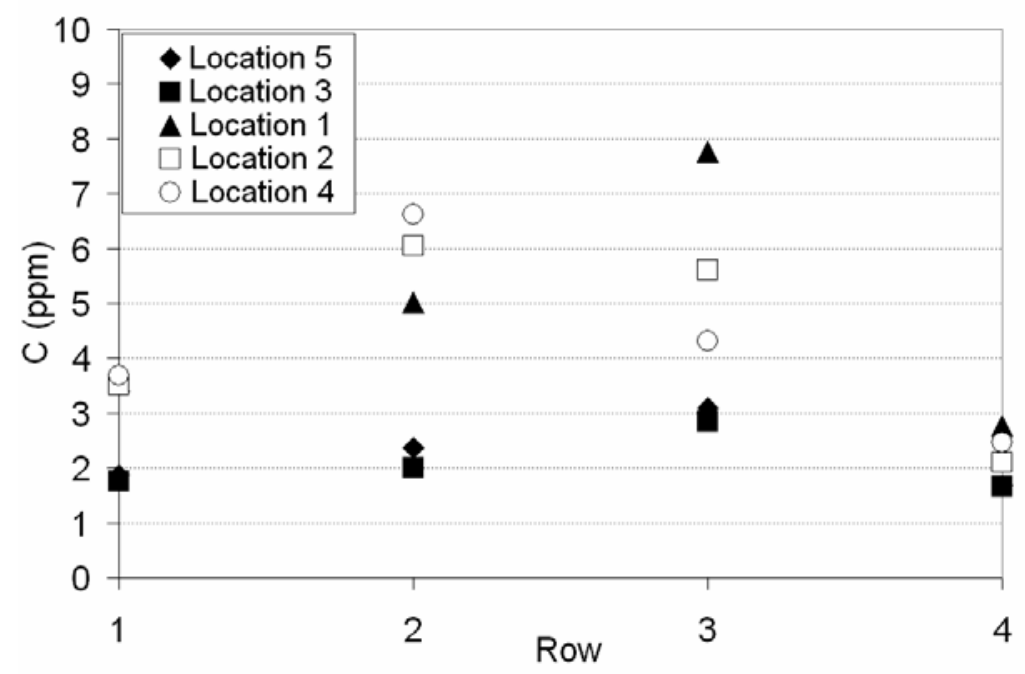

Fig. 8. The sensor responses to the contaminant released from the hand of passenger $3 \mathrm{~K}$ for seating pattern 1

Figure 8 compares the performance of the sensors placed at different locations inside the cabin (refer to Fig. 3). The steady state contaminant concentrations detected by the sensors are shown for a contaminant source near the hand of passenger $3 \mathrm{~K}$ for occupancy pattern 1. Each row had five sensors placed at the locations shown in Fig. 3. The pitch of the sensors between rows is the same as seat distance. The responses of sensors at location 3 and 5 and that at 2 and 4 (refer to Fig. 3) are similar. This implies that the sensors placed at the sides perform similar to those near the outlet. This is because the convective transport in that portion of the cabin is reasonably high due the strong effect of the inlet jet. For a source from passenger $\mathrm{K}$, sensors at location 2 and 4 would of course measure a higher concentration compared to sensors at 3 and 5 because the designed airflow is symmetric in a cross section. The longitudinal transport of contaminant is also evident as sensors at locations 2 and 4 in row 2 could measure higher concentrations than those placed in row 3. However, sensor at location 1 at the ceiling center can still measures a high concentration and its response is 
comparable to the responses of sensor at location 2 and 4 which are closer to the source. It could even measure the highest concentration at row 3 because of the local flow effects. Moreover, the central sensor would definitely be the best for releases near the middle row passengers. Therefore, if only one sensor is available, it should be placed at the center of the cabin ceiling.

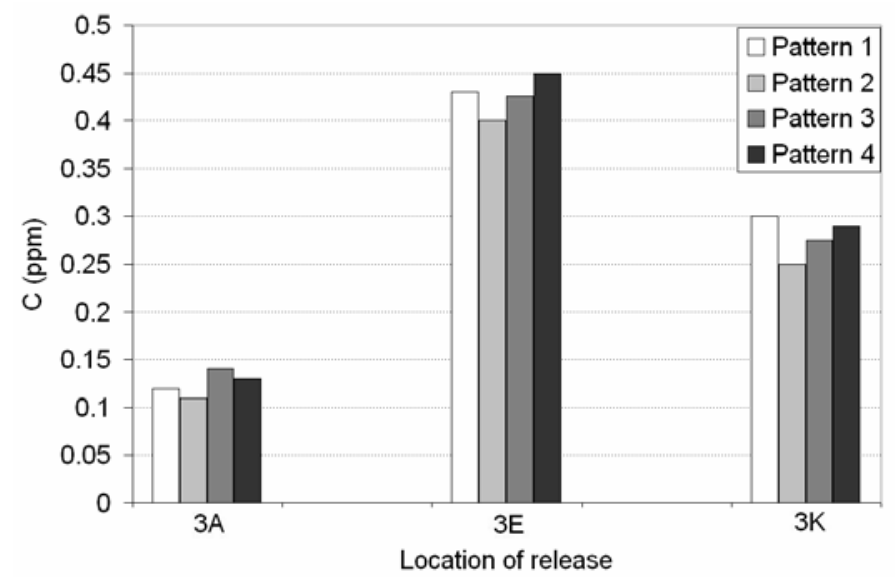

Fig. 9. Detected contaminant concentration of the ceiling center sensor at first row for contaminant released from passengers $3 \mathrm{~A}, 3 \mathrm{E}$ and $3 \mathrm{~K}$

The transient response of a sensor located at cabin ceiling for different release locations is also an important parameter in deciding the placement of sensors. To compare the variation in longitudinal transports for different release locations, Fig. 9 shows the response of a sensor at location 1 placed at first row for contaminant released from the mouth of passengers $3 \mathrm{~A}$, $3 \mathrm{E}$ and $3 \mathrm{~K}$ for $60 \mathrm{~s}$. The results for the four occupancy patterns are very similar because of similar global airflows. Clearly, it is more difficult to detect the contaminant source from the passenger near the window (3A) if the sensor is placed in the center of ceiling. This is because the contaminant travels a long way to reach the ceiling center sensor and is diluted during the transport. Thus if only one sensor is to be used at the middle of the cabin then the release near the window seat would be the most critical.

The comparison of the response times of the ceiling center sensor (location 1) with respect to the sensors at other locations is presented in Figure 10 (a). Each row had five sensors placed at the prescribed locations (refer Fig. 3). The time taken by the sensors to reach $0.1 \mathrm{ppm}$ for contaminant released from the mouth of passengers $3 \mathrm{~A}, 3 \mathrm{E}$ and $3 \mathrm{~K}$ for Pattern 1 is shown in the figure. In general, the sensors at close proximity to the source location fare better. The sensor responses are highly skewed for the source near the window seat because of the symmetric air flow pattern. The overall performance of sensor at location 1 is the best if only one sensor is to be placed. But if more sensors become available, Fig. 10 (a) confirms that the following sensors configurations should be used: sensor locations 4 and 5 if two sensors are used; sensor locations 1, 4, and 5 if three are used; sensor locations 2, 3, 4. and 5 if four are used; and all of them if five are used. The selections are a result of the symmetric air flow pattern in the cabin. Figure 10 (b) shows the decrease of response times with the increase in the number of sensors placed in each row. The decrease is substantial from one sensor (placed at center cabin ceiling) to two (sensors placed at outlets). This is because a 
contaminant released at the middle seats takes lesser time to reach the outlet compared to the time it takes for a contaminant released near the window to get detected by the central sensor as is shown in Fig. 10 (a). Thus the response of the ceiling center sensor for contaminant sources located near the window is the most critical. Hence the full length cabin study is based on the response of the ceiling center sensor for contaminant sources located near windows.

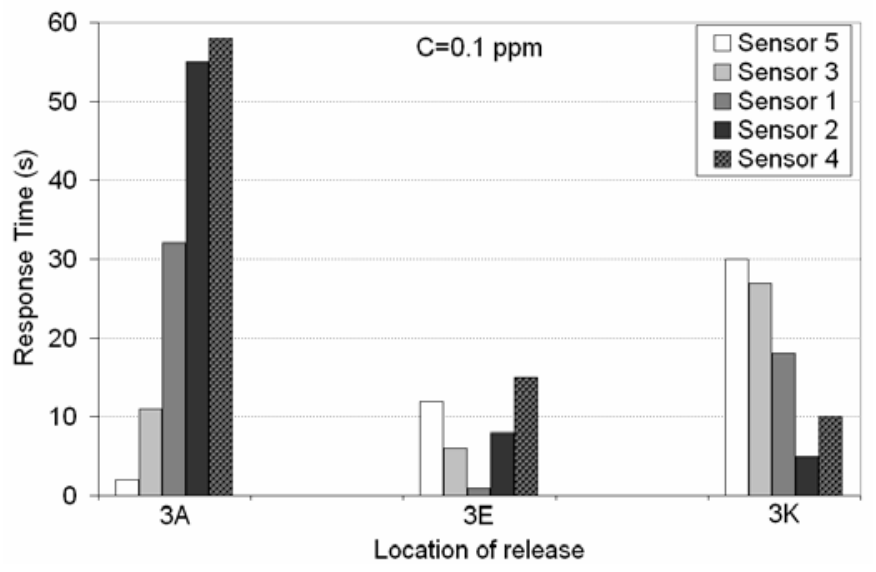

(a)

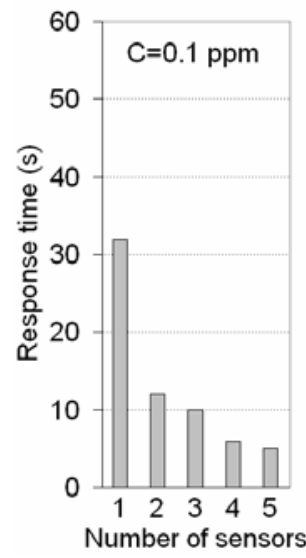

(b)

Fig. 10. (a) Response time for sensors to reach $0.1 \mathrm{ppm}$ for contaminant source from the passenger mouths with seating pattern 1; (b) The change in response time with the increase of sensor number.

\section{Full cabin studies}

Contaminant transport in an airliner cabin is governed by airflow pattern. Fig. 11 shows the representative airflow patterns observed in the first, business, and economy class sections. While the flow patterns along the cross section are symmetric for the business and the economy class sections, it is asymmetric for the first class section. This is due to the different seat arrangements (Fig. 5). The flow pattern along the longitudinal section of the cabin is highly three-dimensional for the first class, due to unsymmetrical seating patterns and the presence of walls at the ends. The longitudinal velocity profiles of the business and economy class are repeatable in the middle rows. 

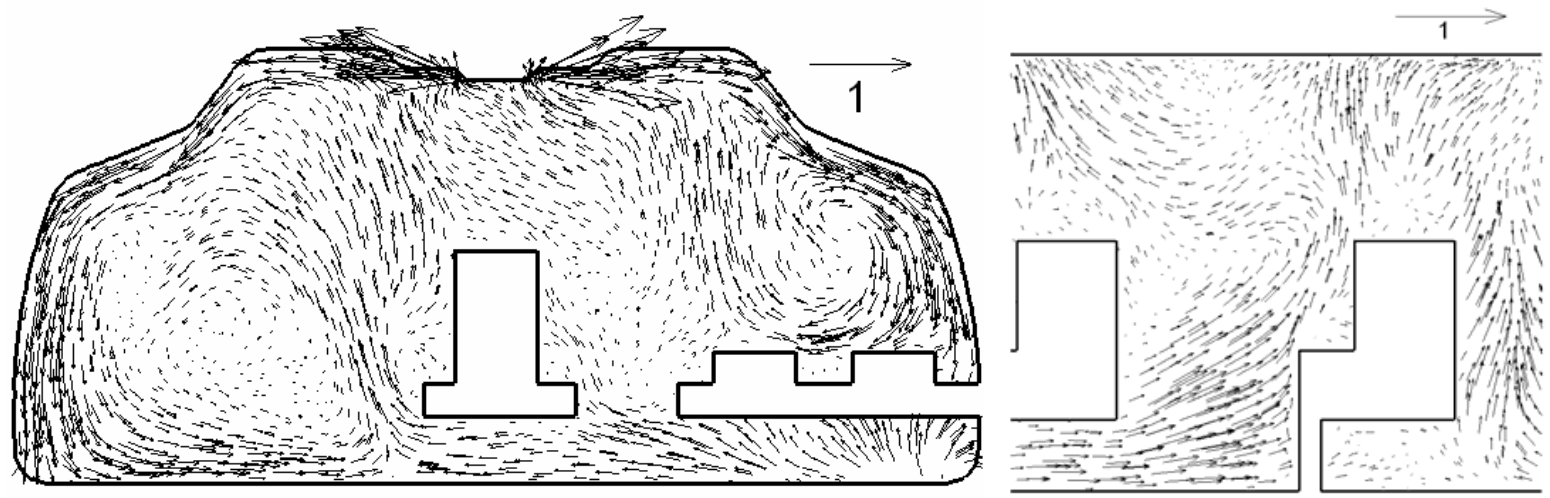

(a)
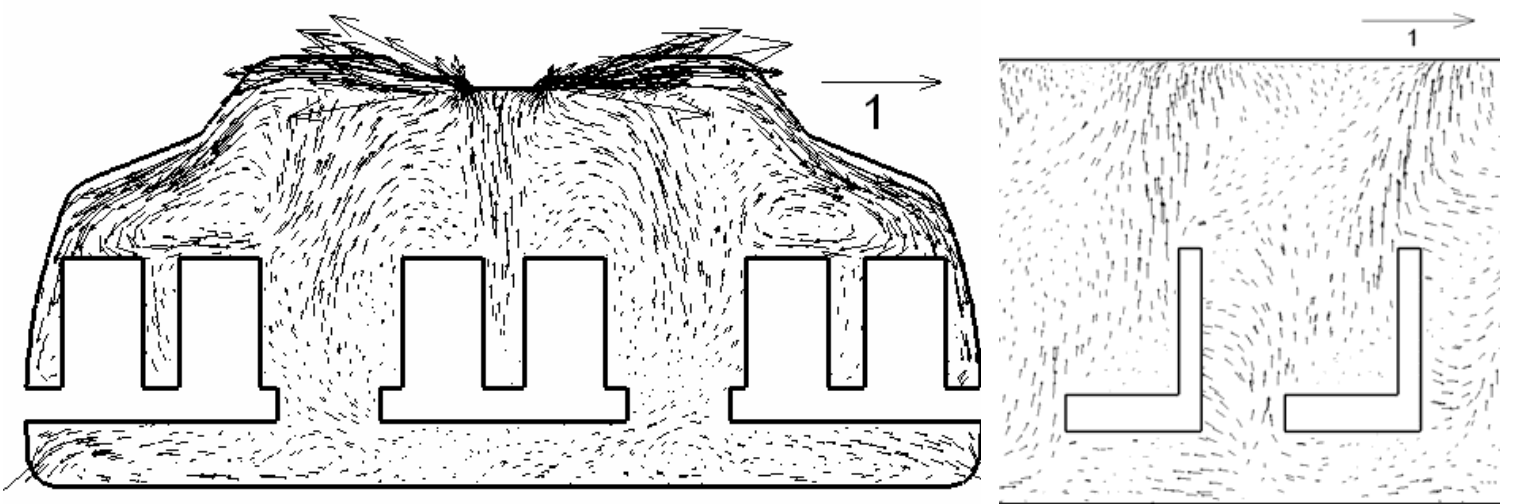

(b)
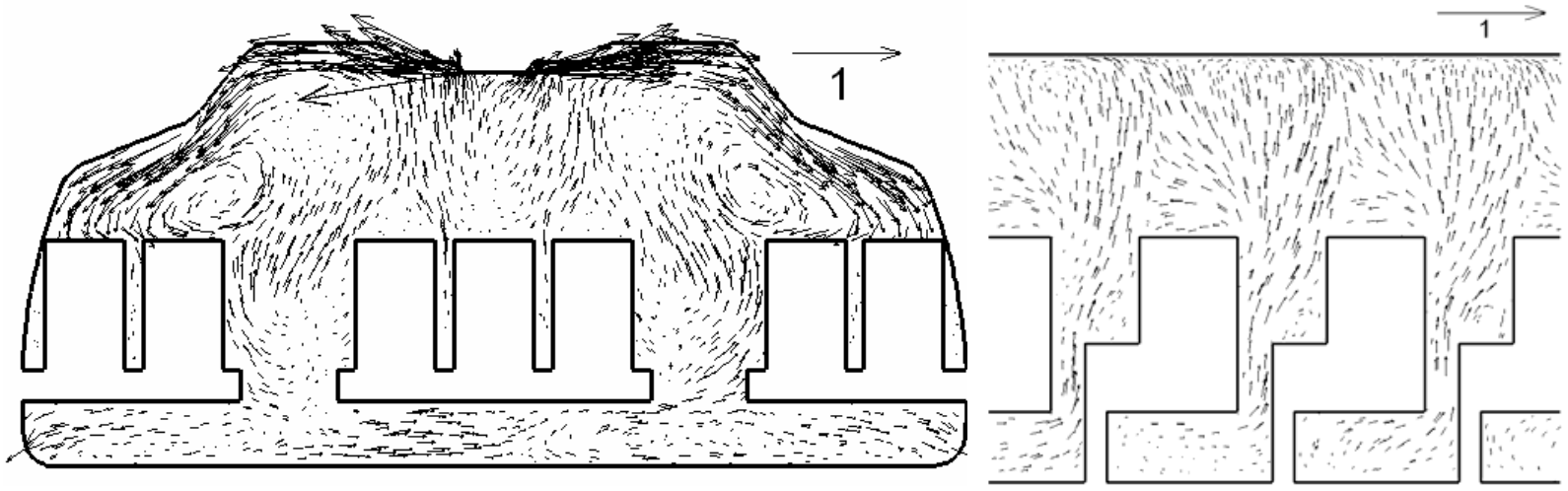

(c)

Fig. 11. Representative airflow patterns along the cross sectional and longitudinal directions of (a) first; (b) business, and (c) economy classes. 
This investigation has also studied unsteady contaminant transport along the longitudinal direction. Figure 12 shows the contaminant concentration distributions at the mid-section of the cabin after the contaminants were released from F1 and B2 for $120 \mathrm{~s}$ (see Fig. 5 for the source locations). The results show that, if a sensor has a detection capability of $0.1 \mathrm{ppm}$, it should be placed every two rows in the first class and every three rows in the business class, respectively. However if a sensor has a detection capability of $0.001 \mathrm{ppm}$, one sensor for the first class and another for the business class will be sufficient to detect contaminant released at these locations.
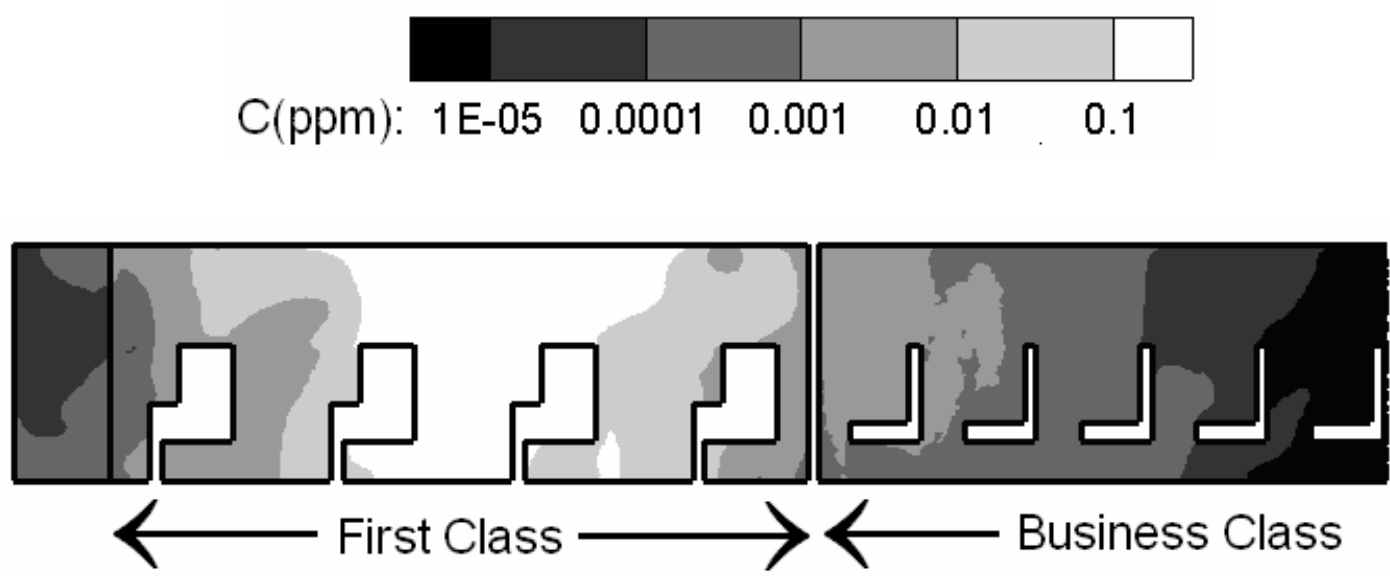

(a)

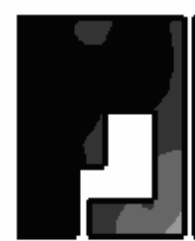

First Class

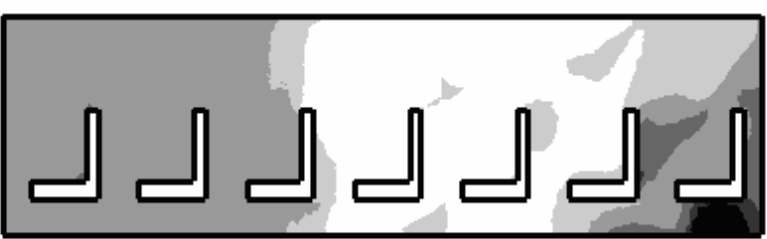

Business Class

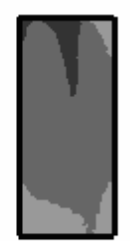

Galley

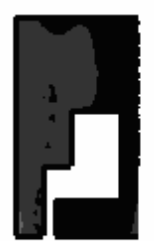

Economy Class

Fig. 12. Contaminant concentration distributions along the longitudinal direction (a) for the first class due to a source released from $F 1$ for $120 \mathrm{~s}$ and (b) for the business class due to a source released from $B 2$ for $120 \mathrm{~s}$.

Figure 13 compares the eight different contaminant release locations along the length of the cabin. The figure shows the number of rows contaminated up to concentration levels of $\mathrm{C}=0.1,0.01$, and $0.001 \mathrm{ppm}$ in the first, business, and economy classes for the different scenarios. Thus for B2 release in business class the number of rows contaminated with $\mathrm{C}=0.1,0.01$, and $0.001 \mathrm{ppm}$ are three, four and seven respectively as is evident from Fig. 12 . Figure 13 shows that for B2 and E2 releases, i.e. contaminant released near the central business and economy class sections, the contaminant transport was similar. This is due to the similar airflow patterns in the business and economy classes. 
The contaminant released by F2, i.e. the last seat of the first class, can affect the passengers in both the first and business classes equally. This is because the first and business class is only separated by a thin wall at the center (refer to Fig. 5). Hence both the first and business class sensors work equally well for such cases.

The contaminant released from B3 in the last row of the business class is the most difficult to detect by the ceiling center sensors because of the presence of galleys at its side. The number of contaminated rows with $\mathrm{C}=0.001 \mathrm{ppm}$ is only three rows in the business-class section compared to seven rows for contaminants released by B2. This is because the contaminant released from B3 passenger distributes evenly in between the huge galley segment behind it and the business class ahead. The release near B3 also presents the worst possible scenario observed near the galleys. The galleys can reduce longitudinal contaminant transports in a given section by more than $50 \%$ if compared to releases near the middle of that section.

The longitudinal transport of contaminant, in terms of the number of rows contaminated and the pitch of seats, is the fastest in the first-class section. This is due to the highly threedimensional airflow pattern observed in the first-class section. The contaminant transport is the slowest for the economy-class. Thus sensor proximity studies based on the economy class would definitely work for the business and first classes.

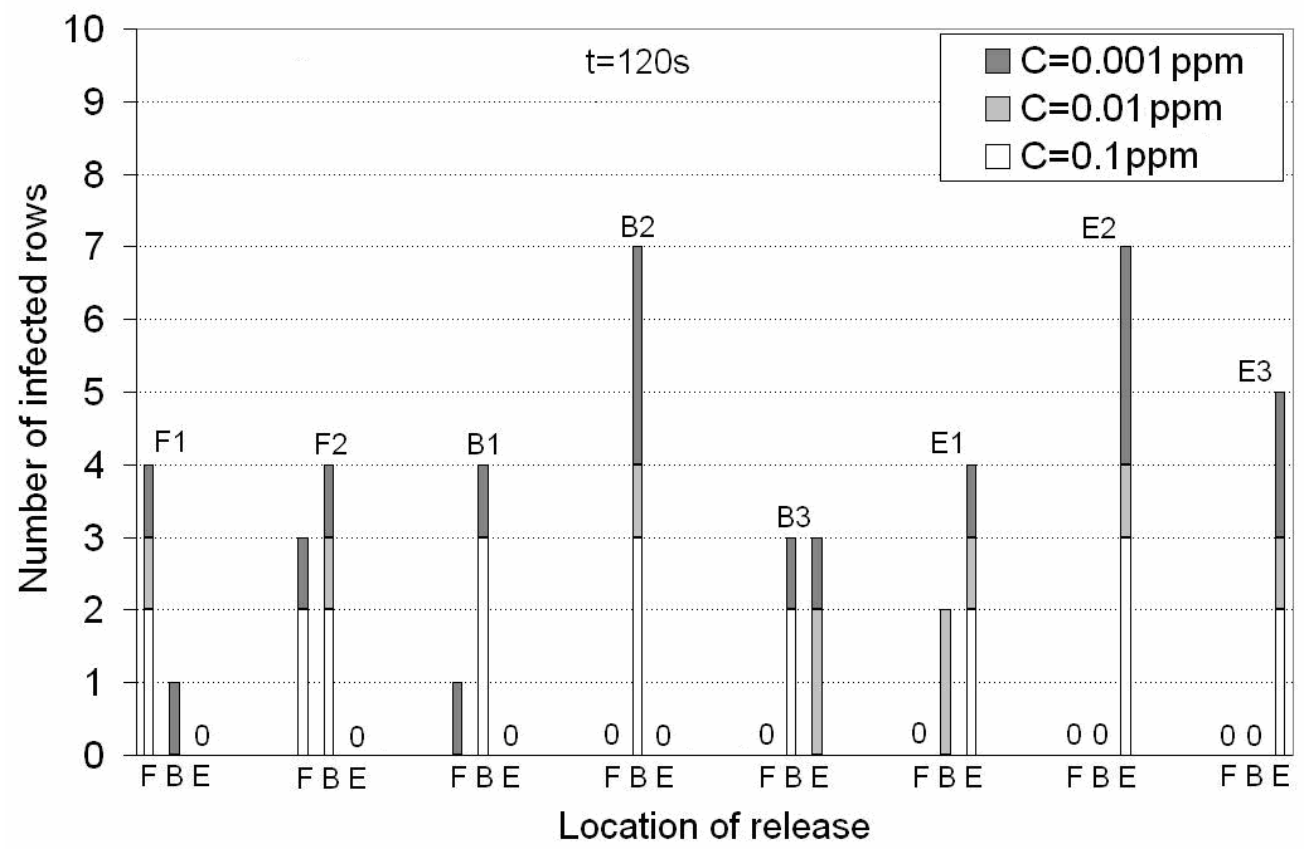

Fig. 13. Number of rows contaminated in 120s for a continuous release (F: First Class, B: Business Class, E: Economy Class) 


\section{Comparison of multipoint with single point sampling systems}

The above study has shown that the galleys can have considerable influence on longitudinal transport of contaminant in a particular section and thus more sensors will be required to address this issue. One way to reduce the required number of the sensors is to use a multiplepoint sampling sensor system. The multiple point sampling would simultaneously collect air from a number of locations and the averaged contaminant concentration of those locations will be detected by a sensor. The sensor systems shown in Fig. 14 were used to compare the performance a single point and a multipoint system for two contaminant release locations in the business class. The single-point sampling system used a single sensor placed at the middle ceiling center of business-class section. The multipoint sampling system extracted air from a total of seven locations (1-7, Fig. 14) along the ceiling center (one location for each row). Then a sensor was used to measure the contaminant concentration in the extracted mixture of air from the seven locations.

Obviously, using the multipoint sensor system would lead to dilution of contaminant concentrations. Other sampling techniques like individual sampling of locations one after another can be used. But it may miss the release of contaminant in short duration. For example, if a release takes place for 30 seconds at B3 and sampling location 3 (Fig. 14) is analyzed. The system would subsequently analyze the locations 4-7 before returning to 1, 2, and 3. It will take a few minutes to complete a sampling cycle and the contaminant gets diluted in this period. In the worst possible case we might not be able to detect anything at all. This would never happen with the multipoint system. Moreover there are other logistic configurations possible as well. But after careful considerations we think the two best options available are the single point and the multipoint systems.

Figure 15 compares the responses of single-point and multipoint sampling systems for the contaminants released from B2 and B3. The single-point sampling system works very effectively for contaminant released from B2 but very poorly for B3. The multipoint sampling system works fine for both the releases. Thus, the multipoint system eliminates the effect of galleys on contaminant sensing.

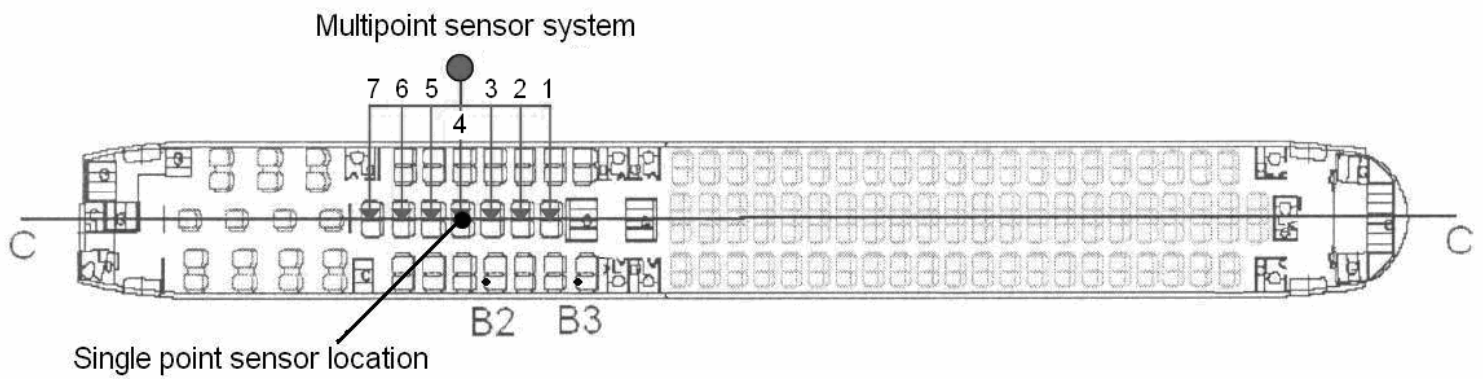

Fig. 14. Schematic of the single and multipoint sampling systems used for detection of contaminant released from B2 and B3 in business-class section 


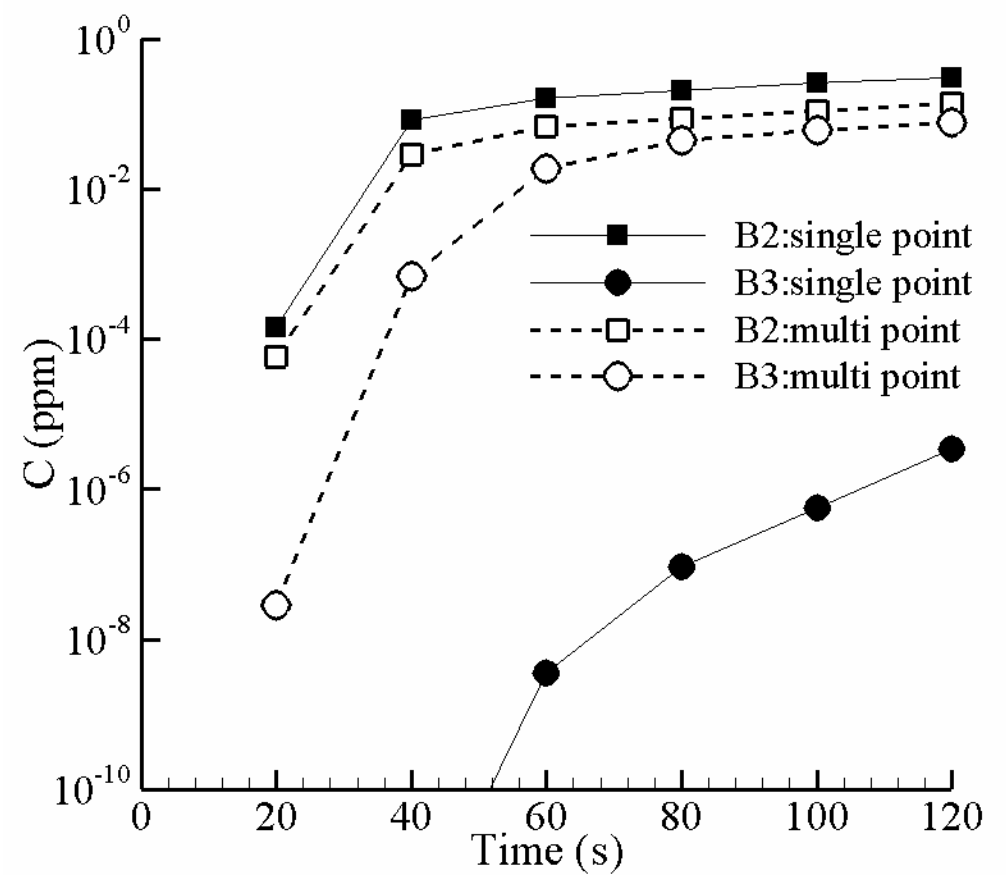

Fig. 15. Responses of the single and multipoint sampling systems in the business-class section for contaminant released from $\mathrm{B} 2$ and $\mathrm{B} 3$

Figure 16 shows the effect of increasing the number of air extraction locations on the performance of a multipoint sampling system in the business-class section with a single sensor for contaminant released from B2. The air is extracted from the seven locations at ceiling center (one location for each row); a total of 14 locations at the two outlets; seven locations at ceiling center and 14 at the two outlets (21 total); 14 above the windows and 14 at the outlets ( 28 total); and all the five sensor locations in each row (35 total). Figure 16 shows that the sensor response improves dramatically if the air is extracted from the 14 locations instead of seven. This is because the contaminant released from B2 is near the outlet. For contaminants released near the middle seats, the sensor detection with the seven air extraction points at ceiling center becomes better. The figure also shows that further increase in the number of extraction points results in a drop of concentration detected by the sensor. Hence more air extraction points do not necessarily improve the performance of the multipoint sampling system. Moreover, the concentrations detected with more than 14 extraction points changes very little after $20 \mathrm{~s}$. Hence the multipoint sampling system is better for the detection of contaminants released for shorter durations. 


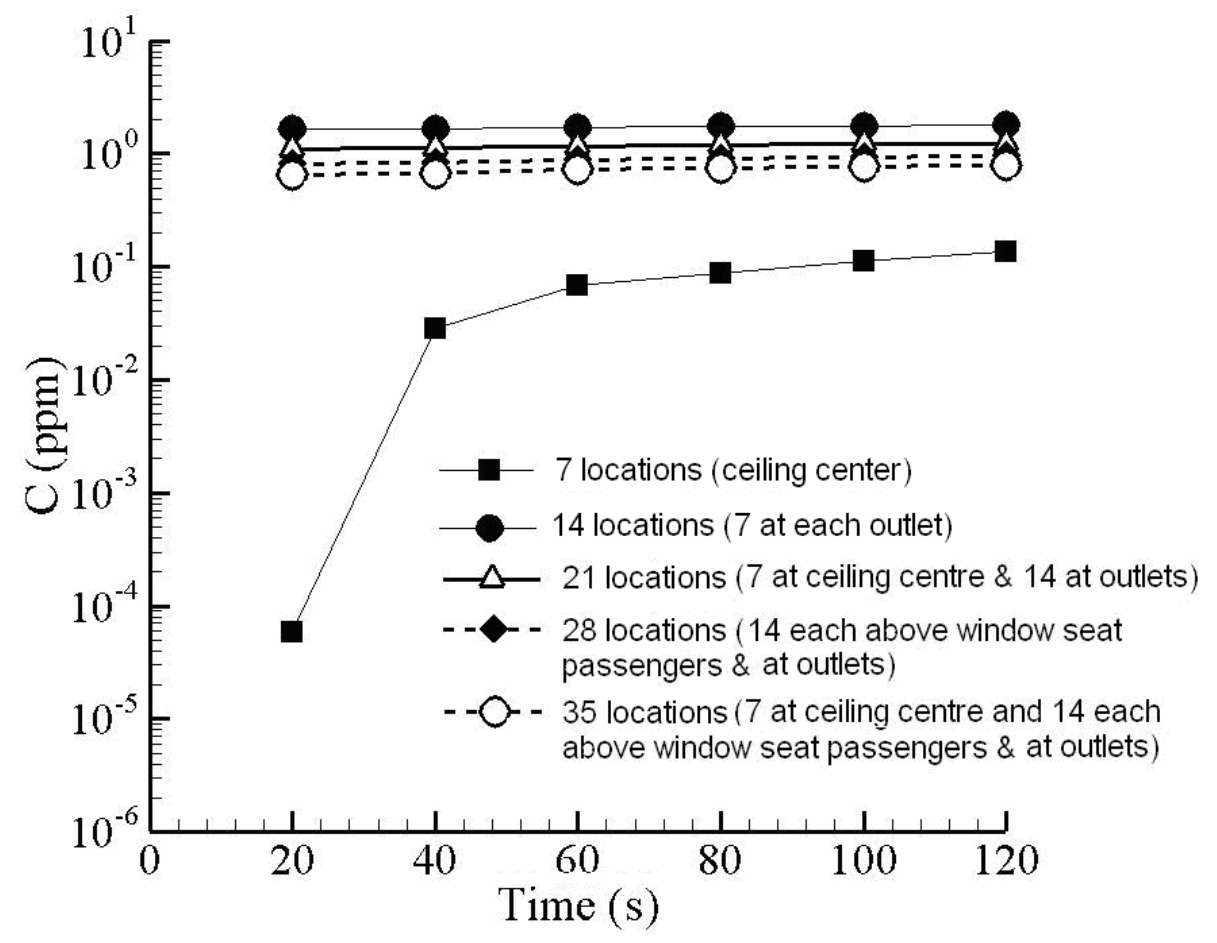

Fig. 16. Response of multipoint sampling system for various air extraction configurations for contaminant released from $\mathrm{B} 2$ in the business class

Figure 17 further compares the number of sensors required for a multipoint sampling system and a single-point sampling system with extracted air from the ceiling center. The comparison used the contaminant distribution obtained at $120 \mathrm{~s}$ from the start of the release from F1, B2 and E2 passengers, respectively. From Figure 13, the B2 release in business class infected three, four and seven rows with $\mathrm{C}=0.1,0.01$, and $0.001 \mathrm{ppm}$, respectively. Thus for the seven-row business-class section, three, two and one sensor would be required to detect the three concentration levels, respectively, with the single-point sensing system. Figure 15 show that the multipoint sampling system can measure a concentration level of 0.1 ppm within $120 \mathrm{~s}$. Thus, only one sensor is sufficient. The results presented in Fig. 17 show that, if the sensor can only detect the contaminant at a concentration of $0.1 \mathrm{ppm}$ or higher, the economy-class section would require eleven (11) sensors by using the single-point sampling system for contaminant released from E2. The number is reduced to three (3) by using the multipoint sampling system. If the detection capability of sensors is $0.001 \mathrm{ppm}$ or lower, then only one sensor is sufficient for the whole cabin if the multipoint sampling system is used. Hence the multipoint sampling system can significantly reduce the number of sensors required. 


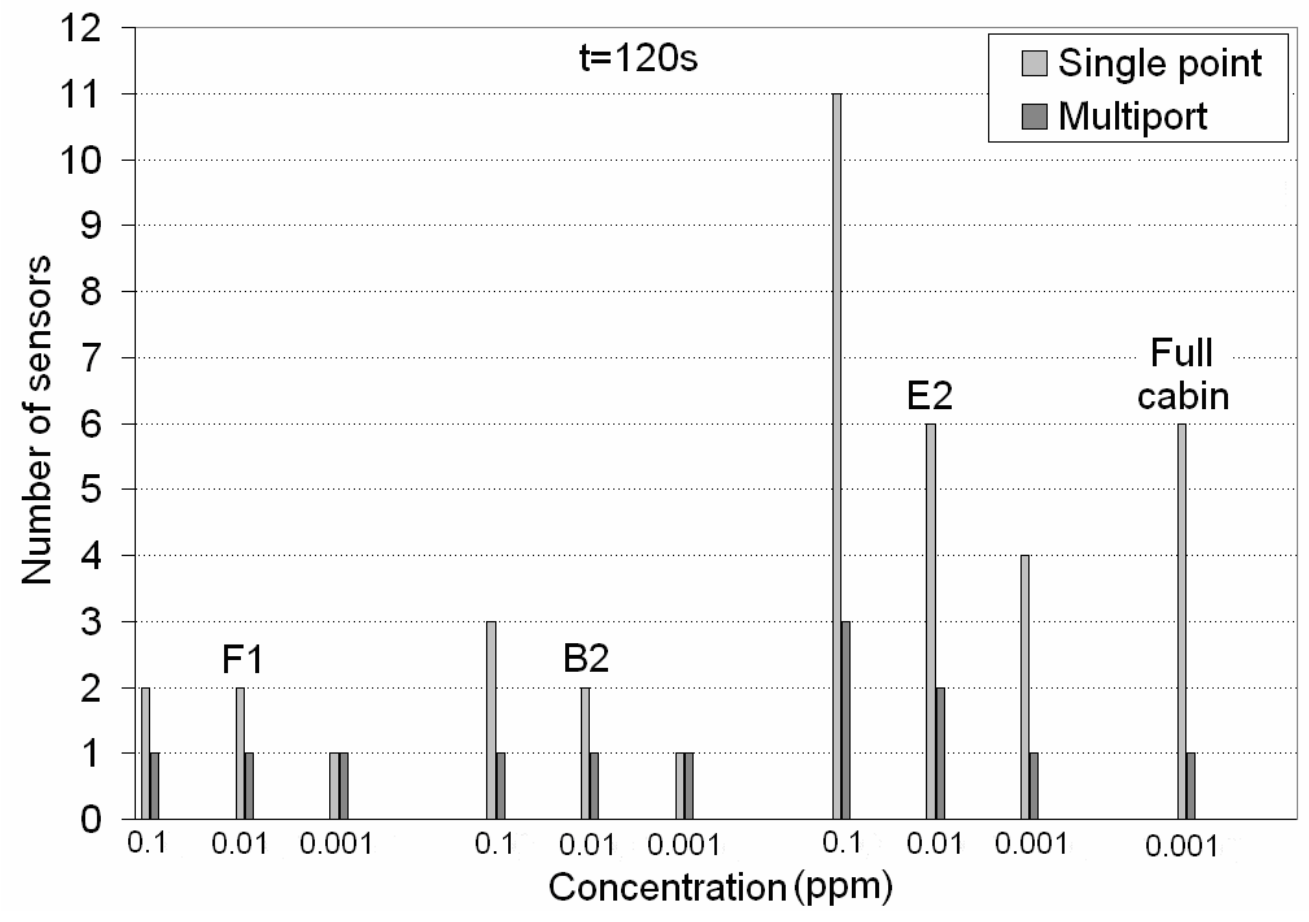

Fig. 17. Comparison of sensor requirement for the multi-point and single-point sampling systems based on the contaminant concentration profiles at $120 \mathrm{~s}$

\section{CONCLUSIONS}

This investigation studied the effect of seating patterns and contaminant source locations on the placement and response of contaminant detection sensors in a twin-aisle commercial aircraft cabin by using a commercial CFD program, FLUENT. FLUENT was validated with the experimental data obtained from a mockup twin-aisle cabin. The study led to the following conclusions:

1. Release locations and seating patterns had little impact on longitudinal contaminant transport but local airflows can cause localized variations.

2. The best location to place a contaminant detection sensor is the center of the cabin ceiling if only one sensor is available. The contaminant released from the window seat passenger would be the most difficult to detect using the sensor.

3. Detection time reduce if more sensors are effectively used. The decrease is substantial from one sensor (placed at cabin center ceiling) to two (sensors placed at the outlets).

4. Seating arrangements can make cross-sectional flow patterns significantly asymmetric.

5. Longitudinal contaminant transport is similar in the business-class and economy-class sections.

6. Galleys can significantly affect longitudinal transport of the contaminants in a particular cabin section.

7. A multipoint sampling system can substantially reduce the number of sensors required and is less sensitive to the effects caused by the galleys. However, increasing 
sampling air extraction points does not necessarily improve the performance of a multipoint sampling system.

\section{ACKNOWLEDGEMENTS}

The authors would like to thank the help extended by Dr. Chao-Hsin Lin of Boeing Commercial Airliner Group, Seattle, WA. This project is funded by the U.S. Federal Aviation Administration (FAA) Office of Aerospace Medicine through the Air Transportation Center of Excellence for Airliner Cabin Environment Research under Cooperative Agreement 04-C-ACE-PU. Although the FAA has sponsored this project, it neither endorses nor rejects the findings of this research. The presentation of this information is in the interest of invoking technical community comment on the results and conclusions of the research.

\section{REFERENCES}

1. M.A. Gendreau and C. DeJohn, New England Journal of Medicine, 2002, 346(14), 1067-73.

2. S.J. Olsen, H.L. Chang, T.Y. Cheung, A.F. Tang, T.L. Fisk, S.P. Ooi, H.W. Kuo, D.D. Jiang, K.T. Chen, J. Lando, K.H. Hsu, T.J. Chen and S.F. Dowell, New England Journal of Medicine, 2003, 349(25), 2416-22.

3. I.A.R. Lakshmanan, Boston Globe, 2003, 1A, 1.

4. A. Mangili and M.A. Gendreau, Lancet, 2005, 365, 989-96.

5. USAMRIID's medical management of biological casualties handbook, U.S. Army Medical Research Institute of Infectious Diseases, 2005, Sixth Edition.

6. http://www.ca.sandia.gov/chembio/facilities protect/protect/index.html

7. A.J. Policastro and S.P. Gordon, APTA Rapid Transit Conference, 2000.

8. T. Zhang and Q. Chen, Building and Environment, 2007, 42(4), 1675-1684.

9. T. Zhang and Q. Chen, Indoor Air, 2007, 17(3), 167-177.

10. Z. Zhai, J. Srebric and Q. Chen, International Journal of Ventilation, 2003, 2(3), 25164.

11. T. Zhang, Q. Chen and C.H. Lin, HVAC\&R Research, 2007, in press.

12. E. Lee, C.E. Feigley, J.A. Khan and J.R. Hussey, Ann. Occup. Hyg., 2006, 50(5), $527-$ 37.

13. T. Mizuno and M. Warfield, ASHRAE Transactions, 1992, 98(2), 329-338.

14. R. Garner, K. Wong and S. Ericson, Proceedings of Annual SAFE Symposium (Survival and Flight Equipment Association), 2003, 248-253.

15. C. Lin, T. Wu, R. Horstman, P. Lebbin, M. Hosni, B. Jones and B. Beck, HVAC\&R Research, 2006, 12(3c), 935-951.

16. A. Singh, M. Hosni and R. Horstman, ASHRAE Transactions, 2002, 108(1), $1005-$ 1013.

17. H. Mo, M. Hosni and B. Jones, ASHRAE Transactions, 2003, 109(2), 101-110.

18. Y. Sun, Y. Zhang, A. Wang, J. Topmiller and J. Bennett, ASHRAE Transactions, 2005, 111(2), 45-52.

19. Y. Zhang, Y. Sun, A. Wang, J. Topmiller and J. Bennett, ASHRAE Transactions, 2005, 111(2), 53-59.

20. J. Arvelo, A. Brandt, R.P. Roger and A. Saksena, ASHRAE Transactions, 2002, 108 (2), 818-25.

21. R.D. Upham, M.S. Thesis, Penn State University, 1997. 
22. NRC (National Research Council), The airliner cabin environment and the health of passengers and crew, 2002, Washington, DC: National Academy Press.

23. T.A. Kenyon, S.E. Valway, W.W. Ihle, I.M. Onorato and K.G. Castro, New England Journal of Medicine, 1996, 334, 933-38.

24. J.D. Spengler and Q. Chen, Annual Review of Energy and the Environment, 2000, 25, 567-600.

25. C.H. Lin, R.H. Horstman, M.F. Ahlers, L.M. Sedgwick, K.H. Dunn, J.L Topmiller, J.S. Bennett and S. Wirogo, ASHRAE Transactions, 2005, 111(1), 755-63.

26. C.H. Lin, R.H. Horstman, M.F. Ahlers, L.M. Sedgwick, K.H. Dunn, J.L Topmiller, J.S. Bennett and S. Wirogo, ASHRAE Transactions, 2005, 111(1), 764-68.

27. Z. Zhang, X. Chen, S. Mazumdar, T. Zhang and Q. Chen, Proceedings of the 10th International Conference on Air Distribution in Rooms, ROOMVENT, 2007, Helsinki, Finland, 171.

28. Q. Chen, Numerical Heat Transfer, Part B, 1995, 28, 353-69.

29. X. Yuan, Q. Chen and L. Glicksman, ASHRAE Transactions, 1999, 105(1), 340-352.

30. G. He, X. Yang, and J. Srebric, Indoor Air, 2005, 15, 367-380.

31. E. U. Finlayson, A. J. Gadgil, T. L. Thatcher, and R. G. Sextro, Indoor Air, 2004, 14, 272-283.

32. D.L. Powers, Boundary value problems and partial differential equation, 2006, Elsevier Academic Press.

33. F. Mermarzadeh and J. Jiang, ASHRAE Transactions, 2000, 106(2), 733-49.

34. M.J. Seymour, http://www.flomerics.com/flovent/technical papers/v17.pdf, Flomerics Ltd., 2001.

35. C. Topp, P. Nielsen and D. Sorensen, ASHRAE Transactions, 2002, 108(2), 1084-89.

36. X. Chen, M.S. Thesis, Purdue University, 2007. 